\title{
Comparative proteomics analysis of normal and memory-deficient Drosophila melanogaster heads
}

\author{
Tian-Ren Lee ${ }^{\dagger}$, Hsiao-Yun Lee ${ }^{\dagger}$, Shun-Hong Huang, Hsin-Tzu Chan, Ping-Chiang Lyu and Hong-Lin Chan*
}

\begin{abstract}
Background: Learning and memory are extremely complex and dynamic processes. Proteins that participate in memory formation are strictly regulated by various pathways and may require protein synthesis and/or posttranslational modifications. To examine the formation of memory, Drosophila was genetically engineered with the mutated memory-related gene, $A m n^{{ }^{8}}$, which induces normal learning and memory behavior within the first 30 min of training. However, the process through which learning occurred could not be retained after the 30 min of training, indicating that these mutants possessed deficits in middle-term memory. A proteomics platform based on two-dimensional differential gel electrophoresis and matrix-assisted laser desorption/ionization time of flight mass spectrometry was employed to examine the head proteome alterations between the wild-type $2 \mathrm{u}$ strain and the memory-deficient mutant $A m n^{X 8}$ strain.

Results: The results indicated that 30 differentially expressed head proteins that mainly function in metabolic pathways and cell structure/cytoskeleton proteins were involved in memory formation. A bioinformatics analysis demonstrated that mitochondrial proteins had critical roles in modulating this process.

Conclusions: This is the first study of a comparative head proteomics analysis of a memory mutant strain and a normal control fruit fly strain. The fundamental proteomics analysis provides potential candidates for further elucidation of the biological mechanism of the memory formation process in Drosophila.
\end{abstract}

Keywords: Drosophila; Brain; Proteomics; 2D-DIGE; Memory

\section{Background}

For nearly a century, the fruit fly, Drosophila melanogaster, has been a powerful and very commonly utilized model organism for studying complex biological problems. Drosophila has served as an invaluable model organism and offers many advantages for the study of human diseases. Benefits include a faster time frame due to the shorter lifespan of flies, numbers of progeny, availability of techniques and tools for manipulating gene expressions, and its well-known anatomy and phenotypes (Venken and Bellen 2005, 2007). Moreover, sequences of the human and fly genomes show an unequivocally high degree of interrelatedness (Adams et al. 2000). Therefore, in the last decade, numerous scientists have tried to gain insights into neurodegenerative diseases by utilizing this model

\footnotetext{
* Correspondence: hlchan@life.nthu.edu.tw

${ }^{\dagger}$ Equal contributors

Institute of Bioinformatics and Structural Biology, and Department of Medical Sciences, National Tsing Hua University, 101 Kuang-Fu Road, Section 2,
} Hsinchu 30013, Taiwan system. Many Drosophila transgenic strains were developed and have been widely applied to study various human diseases such as Alzheimer's, Parkinson's, and Huntington's diseases, and have immensely helped scientists advance our understanding of these complex disorders (Mutsuddi and Nambu 1998; Celotto and Palladino 2005).

Amnesiac (amn), a memory-deficient gene, was first identified by Quinn et al. (1979). It encodes a neuropeptide that is homogeneous with the mammalian pituitary adenylate cyclase-activating peptide, which is related to protein kinase A activity. The amn gene is excessively expressed in two dorsal paired medial neurons, which specifically innervate axon terminals of the entire mushroom body (MB) lobe ensemble. Amn proteins are thought to modulate MB activity in the fruit fly brain (Waddell et al. 2000; Waddell and Quinn 2001). Associated learning/ memory tests were applied to Drosophila melanogaster. Flies with a mutated amn gene possess normal learning and memory behavior within the first 30 min of training. However, memory is impaired after 30 min of training,

\section{Springer}


indicating deficient memory phases in middle-term memory (DeZazzo and Tully 1995; Tully and Quinn 1985).

Proteomics is the global-scale study of protein expression levels and post-translational modifications in the post-genomic era. This method is able to globally examine cellular processes at the protein level in cells, tissues, and organisms (Timms 2008). In order to analyze differential protein expressions across different samples, improvements in existing techniques such as two-dimensional gel electrophoresis (2-DE) became essential. Recently, twodimensional differential gel electrophoresis (2D-DIGE) was introduced as a fluorescence-based strategy that increases the usefulness of the proteomics technique by allowing different protein samples to be labeled with distinct fluorescent dyes and run on the same gel (Timms and Cramer 2008). Although the 2D-DIGE technique is derived from traditional two-dimensional polyacrylamide gel electrophoresis (2D-PAGE), 2D-DIGE can overcome many disadvantages of classical 2-DE. For example, the 2D-DIGE approach can eliminate gel-to-gel variations. Protein samples are initially labeled with different fluorescent dyes. Each dye has a distinct fluorescent wavelength allowing two or three different samples to be concurrently separated on the same gel. Thus, comparisons across different samples can be made with confidence (Timms and Cramer 2008; Lai et al. 2010). With this effective technique, it is now possible to simultaneously and reproducibly separate around 2,000 different proteins (Hung et al. 2010, 2011; Huang et al. 2010; Lai et al. 2010; Chen et al. 2011; Chou et al. 2010). Individual proteins can be identified by a subsequent mass spectrometric analysis combined with searches of public protein databases.

Learning and memory are common and important behaviors for animals. In this study, we performed 2D-DIGE to compare the protein expression pattern of a Drosophila melanogaster wild-type (WT) strain $(2 u)$ with that of a memory-deficient mutant $\left(A m n^{X 8}\right)$ which can only maintain normal memory behavior for $30 \mathrm{~min}$. To our knowledge, this is the first publication on a comparative head proteomics analysis of a memory mutant strain and a normal control fruit fly strain to elucidate which proteins are involved in the process of learning and memory formation.

\section{Methods}

\section{Chemicals and reagents}

Generic chemicals were purchased from Sigma-Aldrich (St. Louis, MO, USA), while reagents for 2D-DIGE were purchased from GE Healthcare (Uppsala, Sweden). All chemicals and biochemicals used in this study were of analytical grade.

\section{Drosophila strains}

Drosophila melanogaster WT $(2 u)$ and memory-deficient mutant strains $\left(A m n^{X 8}\right)$ used in this study were provided by the laboratory of Prof. Ann-shing Chiang at the Brain Research Center, National Tsing Hua University (Hsinchu, Taiwan). All flies were reared in a temperature-controlled incubator which was maintained at $25^{\circ} \mathrm{C}$ with $70 \%$ relative humidity on a cycle of $12 \mathrm{~h}$ of light and $12 \mathrm{~h}$ of dark conditions. Flies were raised and maintained on food containing culture medium $(0.9 \%$ agar medium containing $10.5 \%$ dextrose, $5 \%$ cornmeal, $2.6 \%$ baker's yeast, and $0.23 \%$ tegocept, to which active yeast was added) in glass bottles. Flies were raised in culture medium for $4 \sim 7$ days after eclosion. Mature flies were then transferred to a new culture medium and were reared under the same conditions before being sacrificed.

\section{Sample preparation for the proteomics analysis}

Drosophila melanogaster strains were separately collected into centrifuge tubes $(50 \mathrm{ml})$, frozen in liquid nitrogen, and vigorously shaken to separate heads from bodies and extremities. Fly heads were isolated using pre-chilled size-exclusion sieves. The top sieve (Tyler equivalent 25 mesh\#, $0.71 \mathrm{~mm}^{2}$ ) allowed the heads to pass to the bottom sieve (Tyler equivalent 40 mesh\#, $0.42 \mathrm{~mm}^{2}$ ), which separated the extremities from the heads. The heads were collected and pulverized in liquid nitrogen with a pre-chilled mortar and pestle and then transferred to a micro-centrifuge tube. All samples were subjected to methanol/chloroform precipitation for protein extraction and purification according to a previously described protocol (Ericsson 1999) with slight modifications. Samples were suspended in lysis buffer consisting of $7 \mathrm{M}$ urea, $2 \mathrm{M}$ thiourea, and 4\% (w/v) 3-[(3cholamidopropyl)-dimethylammonio]-1-propanesulfonate) followed by extraction with methanol, chloroform, and double-deionized water $\left(\mathrm{ddH}_{2} \mathrm{O}\right)$. Prior to adding each solution, samples were vortexed and centrifuged at $14,000 \mathrm{rpm}$ for $5 \mathrm{~min}$. The top aqueous layer of all samples was discarded. Subsequently, samples were washed with methanol and centrifuged again at 14,000 rpm for $5 \mathrm{~min}$. Finally, as much of the top methanol layer as possible was removed, and samples were vacuum-dried in a SpeedVac (Thermo Scientific, Waltham, MA, USA). Lysates were homogenized by injection through a 25-gauge needle six times, and insoluble substances were removed by centrifugation at $14,000 \mathrm{rpm}$ at $4^{\circ} \mathrm{C}$ for $30 \mathrm{~min}$. Protein concentrations were determined using a Bradford protein assay kit (Bio-Rad, Hercules, CA, USA).

\section{D-DIGE, gel image analysis, protein staining, and in-gel digestion}

The experimental protocols for the expression of 2DDIGE, gel image analysis, protein staining, and in-gel digestion were described in our previous publications (Chan et al. 2005; Gharbi et al. 2002; Lai et al. 2010; Chen et al. 2011). Briefly, protein samples were labeled 
with [ $N$-hydroxy succinimidyl] ester derivatives of the cyanine dyes $\mathrm{Cy} 2, \mathrm{Cy} 3$, and Cy5. A protein sample at $100 \mu \mathrm{g}$ in triplicate was minimally labeled with $250 \mathrm{pmol}$ of either Cy3 or Cy5 for comparison on the same 2-DE gel. To facilitate image matching and cross-gel statistical comparisons, a pool of all samples was also prepared and labeled with $\mathrm{Cy} 2$ at a molar ratio of 2.5 pmol Cy 2 per microgram of protein as an internal standard that was run on all gels. Labeling reactions were performed for $30 \mathrm{~min}$ on ice in the dark and then quenched with a 20-fold molar excess of free L-lysine to the dye for $10 \mathrm{~min}$. Differentially Cy3- and Cy5-labeled samples were then mixed with the
Cy2-labeled internal standard and reduced with dithiothreitol for $10 \mathrm{~min}$. Immobilized nonlinear $\mathrm{pH}$ gradient (IPG) buffer, at $\mathrm{pH} 3$ to $10(2 \%(v / v)$ (GE Healthcare, Uppsala, Sweden)) was added, and the final volume was adjusted to $450 \mu \mathrm{L}$ with $2 \mathrm{D}$-lysis buffer for overnight rehydration into IPG strips (pH 3 to 10, $24 \mathrm{~cm}$ ). Isoelectric focusing was then performed using a Multiphor II apparatus (GE Healthcare) for a total of $62.5 \mathrm{kVh}$ at $20^{\circ} \mathrm{C}$. Strips were then equilibrated in $6 \mathrm{M}$ urea, $30 \%(v / v)$ glycerol, $1 \%$ sodium dodecylsulfate (SDS) $(w / v), 100 \mathrm{mM}$ Tris- $\mathrm{HCl}(\mathrm{pH} 8.8)$, and $65 \mathrm{mM}$ dithiothreitol for $15 \mathrm{~min}$ and then in the same buffer containing $240 \mathrm{mM}$

Table 1 Differentially expressed proteins between $2 u$ and $A m n^{x 8}$ flies by MALDI-TOF peptide mass fingerprinting after 2D-DIGE

\begin{tabular}{|c|c|c|c|c|c|c|}
\hline $\begin{array}{l}\text { Spot } \\
\text { number }\end{array}$ & Protein name & $\begin{array}{l}\text { Theoretical } \\
\mathrm{MW}(\mathrm{Da}) / \mathrm{pl}\end{array}$ & $\begin{array}{l}\text { Observe } \\
\mathrm{MW}(\mathrm{Da}) / \mathrm{pl}\end{array}$ & Score & $\begin{array}{l}\text { Queries } \\
\text { matched }\end{array}$ & Coverage (\%) \\
\hline 112 & Drosocrystallin & $55,248 / 5.54$ & $130,000 / 5.5$ & 90 & 12 & 40 \\
\hline 285 & Transferrin precursor & $72,964 / 6.69$ & $90,000 / 6.7$ & 161 & 15 & 31 \\
\hline 297 & Tropomyosin-1, isoforms 33/34 & $54,666 / 4.77$ & $90,000 / 4.5$ & 79 & 13 & 38 \\
\hline 300 & Tropomyosin-2 & $32,961 / 4.39$ & $40,000 / 4.8$ & 122 & 19 & 25 \\
\hline 324 & Heat shock $70-k D a$ protein cognate 4 & $71,372 / 5.36$ & $72,000 / 5.5$ & 83 & 12 & 26 \\
\hline 351 & Phosphoenolpyruvate carboxykinase (GTP) & $71,482 / 7.50$ & $71,000 / 7.0$ & 142 & 19 & 31 \\
\hline 363 & Esterase-6 & $61,486 / 5.57$ & $68,000 / 5.7$ & 233 & 21 & 48 \\
\hline 408 & $\begin{array}{l}\text { Succinate dehydrogenase [ubiquinone] flavoprotein } \\
\text { subunit, mitochondrial }\end{array}$ & $72,868 / 6.65$ & $66,000 / 6.3$ & 108 & 27 & 48 \\
\hline 513 & Actin & $42,072 / 5.29$ & $58,000 / 5.5$ & 112 & 11 & 43 \\
\hline 562 & Actin & $42,072 / 5.29$ & $55,000 / 5.3$ & 67 & 10 & 30 \\
\hline 571 & Actin & $42,072 / 5.29$ & $55,000 / 5.5$ & 80 & 10 & 37 \\
\hline 642 & Enolase & $54,561 / 8.68$ & $54,500 / 6.3$ & 134 & 13 & 39 \\
\hline 675 & CG2233-PA (GH20802p) & $47,107 / 5.95$ & $47,000 / 5.9$ & 167 & 18 & 48 \\
\hline 679 & Gene P1 protein & $119,350 / 5.82$ & $47,000 / 6.4$ & 81 & 14 & 18 \\
\hline 711 & Vitellogenin II precursor & $49,762 / 7.74$ & $46,500 / 6.4$ & 90 & 14 & 49 \\
\hline 716 & Vitellogenin I precursor & $48,739 / 7.19$ & $46,500 / 5.9$ & 134 & 20 & 41 \\
\hline 740 & Isocitrate dehydrogenase, isoform D & $46,729 / 5.93$ & $46,000 / 6.4$ & 54 & 10 & 28 \\
\hline 750 & Actin & $42,072 / 5.29$ & $45,000 / 5.3$ & 95 & 10 & 34 \\
\hline 958 & Aldehyde reductase & $36,185 / 6.21$ & $36,000 / 6.2$ & 154 & 14 & 61 \\
\hline 959 & CG9119-PA (GH07301p) & $35,866 / 5.96$ & $39,000 / 6.0$ & 83 & 9 & 40 \\
\hline 982 & Glycerol-3-phosphate dehydrogenase & $39,627 / 6.33$ & $38,500 / 6.5$ & 84 & 11 & 36 \\
\hline 989 & Glycerol-3-phosphate dehydrogenase & $39,627 / 6.33$ & $38,500 / 6.8$ & 84 & 16 & 36 \\
\hline 994 & Glycerol-3-phosphate dehydrogenase & $39,627 / 6.33$ & $38,500 / 6.5$ & 72 & 13 & 38 \\
\hline 1000 & Glycerol-3-phosphate dehydrogenase & $39,627 / 6.33$ & $38,500 / 6.8$ & 87 & 12 & 44 \\
\hline 1017 & IP10437p (Fragment) & $36,568 / 6.79$ & $38,500 / 7.5$ & 138 & 12 & 46 \\
\hline 1029 & Probable transaldolase & $36,939 / 7.55$ & $38,000 / 6.0$ & 120 & 15 & 47 \\
\hline 1139 & 14-3-3 protein & $28,210 / 4.77$ & $29,000 / 4.7$ & 61 & 13 & 38 \\
\hline 1234 & Ferritin 2 light chain homolog & $25,489 / 5.90$ & $26,000 / 6.3$ & 183 & 14 & 63 \\
\hline 1380 & Cofilin/actin-depolymerizing factor homolog & $17,428 / 6.74$ & $20,000 / 5.8$ & 126 & 14 & 70 \\
\hline 1502 & Proteasome endopeptidase complex & $26,004 / 6.21$ & $26,000 / 5.5$ & 93 & 9 & 43 \\
\hline
\end{tabular}


iodoacetamide for a further $15 \mathrm{~min}$. Equilibrated IPG strips were transferred onto $24 \times 20$-cm $12.5 \%$ polyacrylamide gels cast between low-fluorescence glass plates and bonded to one of the plates. The strips were overlaid with $0.5 \%(w / v)$ low-melting-point agarose in running buffer containing bromophenol blue. Gels were run in an Ettan Twelve gel tank (GE Healthcare) at $4 \mathrm{~W}$ per gel at $10^{\circ} \mathrm{C}$ until the dye front had completely run out of the bottom of the gels. Gels were then directly scanned between the glass plates using an Ettan DIGE Imager (GE Healthcare) according to the manufacturer's instructions. An image analysis was performed using DeCyder 2-D Differential Analysis Software vers. 7.0 (GE Healthcare) to co-detect, normalize, and quantify the protein features in the images. Features detected from nonprotein sources were filtered out. Spots displaying an average of a $\geq 1.5$-fold increase or decrease in abundance with a $p$ value $<0.05$ were selected for protein identification.

Colloidal Coomassie blue G-250 staining was used to visualize CyDye-labeled protein features in 2-DE. Bonded gels were fixed in 30\% v/v ethanol and 2\% v/v phosphoric acid overnight, washed three times (for 30 min each) with $\mathrm{ddH}_{2} \mathrm{O}$, and then incubated in $34 \% \mathrm{v} / v$ methanol, $17 \% w / v$ ammonium sulfate, and $3 \% v / v$ phosphoric acid for $1 \mathrm{~h}$ prior to adding $0.5 \mathrm{~g} / \mathrm{L}$ Coomassie blue G-250. Gels were then left to stain for 5 to 7 days. Stained

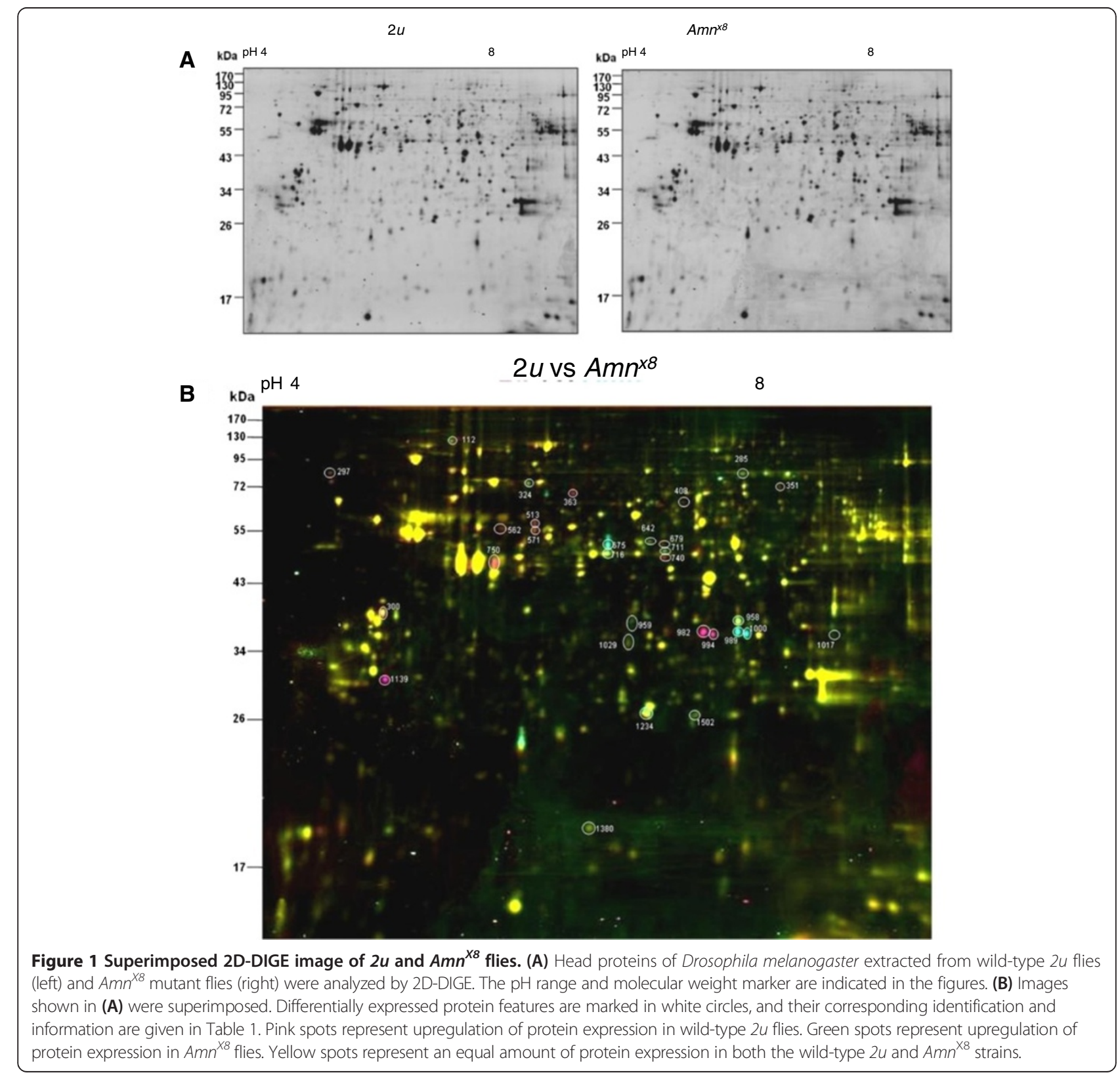


gels were imaged on an ImageScanner III densitometer (GE Healthcare).

Excised post-stained gel pieces were washed three times in 50\% acetonitrile (ACN), dried in a SpeedVac for $20 \mathrm{~min}$, reduced with $10 \mathrm{mM}$ dithiothreitol in $5 \mathrm{mM}$ ammonium bicarbonate $\mathrm{pH} 8.0$ (AmBic) for $45 \mathrm{~min}$ at $50^{\circ} \mathrm{C}$, and then alkylated with $50 \mathrm{mM}$ iodoacetamide in $5 \mathrm{mM}$ AmBic for $1 \mathrm{~h}$ at room temperature in the dark. Gel pieces were then washed three times in 50\% ACN and vacuum-dried before reswelling with $50 \mathrm{ng}$ of modified trypsin (Promega, Madison, WI, USA) in $5 \mathrm{mM}$ AmBic. The pieces were then overlaid with $10 \mu \mathrm{L}$ of $5 \mathrm{mM}$ AmBic and trypsinized for $16 \mathrm{~h}$ at $37^{\circ} \mathrm{C}$. Supernatants were collected, peptides were further extracted twice with $5 \%$ trifluoroacetic acid in $50 \% \mathrm{ACN}$, and the supernatants were pooled. Peptide extracts were vacuumdried, resuspended in $5 \mu \mathrm{L} \mathrm{ddH}_{2} \mathrm{O}$, and stored at $-20^{\circ} \mathrm{C}$ prior to the mass spectrometry (MS) analysis.
Protein identification by matrix-assisted laser desorption ionization time of flight mass spectrometry

For protein identification, extracted peptides were subjected to peptide mass fingerprinting (PMF) by matrixassisted laser desorption ionization time of flight mass spectrometry (MALDI-TOF MS). Details of the MALDITOF MS analysis were described in our previous report (Lai et al. 2010). Briefly, the PMFs were acquired using an Autoflex III MS (Bruker Daltonics, Bremen, Germany) in reflector mode. The spectrometer was calibrated with a peptide calibration standard (Bruker Daltonics), and internal calibration was performed using trypsin autolysis peaks at $m / z 842.51$ and $2,211.10$. Peaks in the mass range of $m / z 800$ to 3,000 were used to generate a PMF that was used to search the MSDB, NCBI, and Swiss-Prot/TrEMBL databases (vers. 57.12; 513,877 entries) using Mascot software vers. 2.2.04 (Matrix Science, London, UK). The following parameters were used: Drosophila melanogaster,

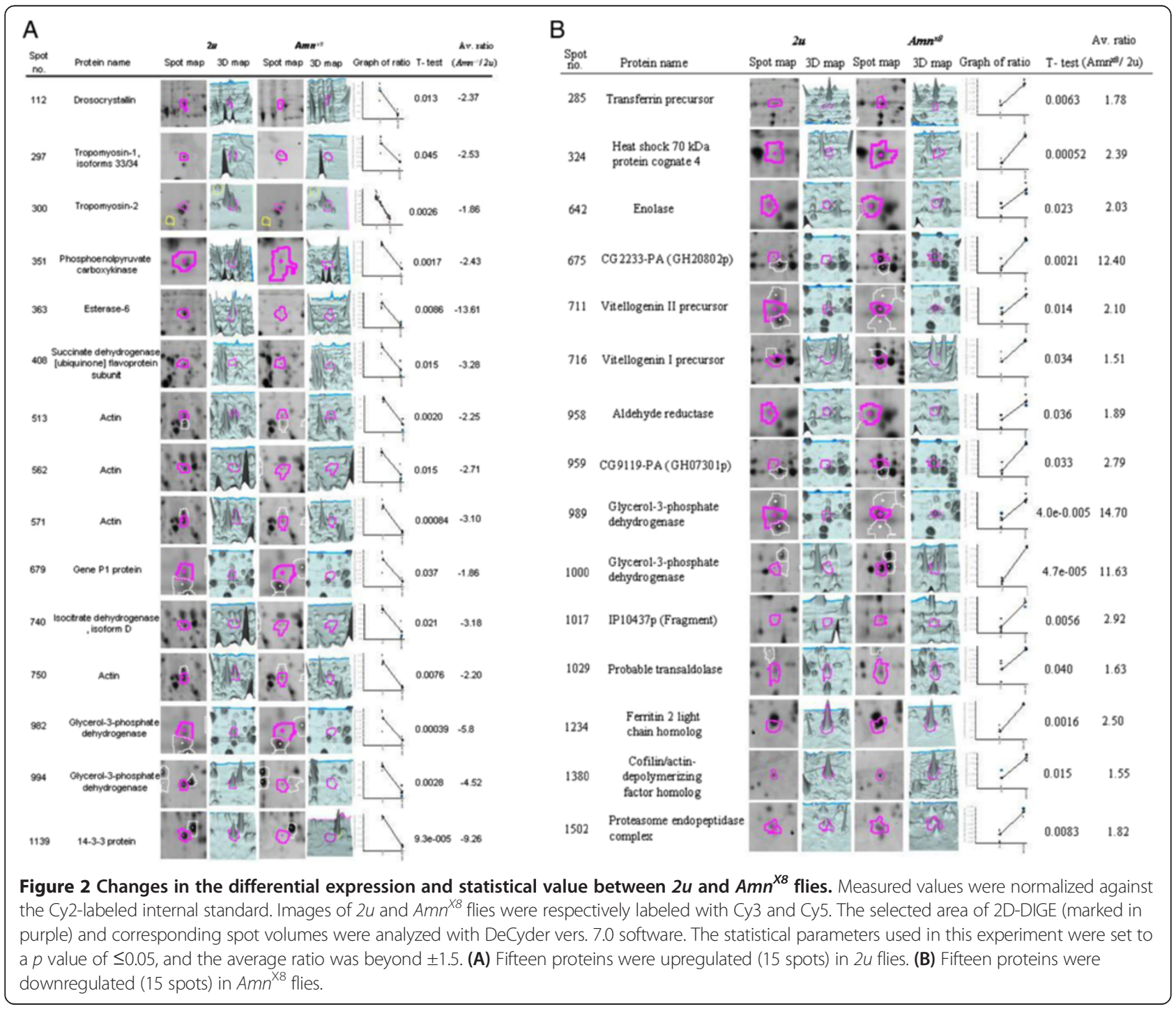


tryptic digest with a maximum of one missed cleavage, carbamidomethylation of cysteine, partial protein $\mathrm{N}$ terminal acetylation, partial methionine oxidation, partial modification of glutamine to pyroglutamate, and a mass tolerance of $50 \mathrm{ppm}$. Identifications were accepted based on significant MASCOT scores $(p<0.05)$, at least four peptides per protein, spectral annotation, observed versus expected molecular weights, and the value of the isoelectric point $(\mathrm{p} I)$ on $2-\mathrm{DE}$.

\section{Results}

Drosophila melanogaster is one of the most studied eukaryote model systems used to examine many cellular processes including diseases, infections, behaviors, memory formation, and development. Previous reports indicated that memory formation is a process of protein synthesis and/or post-translational modification (Barco et al. 2002; Dubnau et al. 2003). In order to establish a highthroughput platform for identification of memory-related gene expression changes in Drosophila melanogaster, the highly sensitive 2D-DIGE technique was employed for proteome comparisons. After fluorescence dye labeling, proteins from different sources can easily be detected with a fluorescence scanner. Each image was displayed with pseudo-colors, and images of the $2 u$ and $A m n^{X 8}$ strains were respectively displayed as pink and green. Yellow spots indicated an equal amount of protein expression in both the WT $2 u$ and $A m n^{X 8}$ strains. In order to conveniently observe and compare protein profiles of the $2 u$ and $A m n^{X 8}$ strains, 2D images of the $2 u$ and $A m n^{X 8}$ strains were superimposed. Triplicate experiments were subsequently analyzed using DeCyder ${ }^{\mathrm{m}} \mathrm{s}$ software, and spots with significant changes were selected for protein identification by MS (Table 1, Figure 1). Results indicated that more than 2,000 spots were defined, among which 30 proteins that differed in protein expression levels between the $2 u$ and $A m n^{X 8}$ strains were identified. Among these identified proteins, 15 protein spots were observed to have been upregulated in the WT $2 u$ strain. In contrast, 15 spots were observed to have been upregulated in the mutant strain $A m n^{X 8}$ (Table 1). Their 2D-PAGE maps, three-dimensional patterns, and statistical information are shown in Figure 2. Because we were interested in the roles of those proteins during memory formation, the proteins were classified into seven different groups according to their functions: metabolic pathway (43.3\%); cell structure and mobility proteins (23\%); protein folding, sorting, and degradation (3.3\%); transport proteins (6.67\%); neuron development (3.3\%); others (16.7\%); and function unknown (3.3\%) (Table 2). These proteins may be involved in memory formation. However, detailed relationships across these identified proteins are yet to be investigated. Accordingly, all of the identified proteins were uploaded into the STRING protein interaction database (http://string.embl.de/), and the
Table 2 List of identified proteins from $2 u$ and $A m n^{X 8}$ flies grouped in functional categories

\begin{tabular}{ll}
\hline Functional categories & Identified proteins \\
\hline Metabolic pathway & 351. Phosphoenolpyruvate carboxykinase \\
363. Esterase-6 & 408. Succinate dehydrogenase [ubiquinone] \\
flavoprotein subunit & 642. Enolase \\
& 740. Isocitrate dehydrogenase, isoform D \\
& 958. Aldehyde reductase \\
& 959. CG9119-PA (GH07301p) \\
& 982. Glycerol-3-phosphate dehydrogenase \\
& 989. Glycerol-3-phosphate dehydrogenase \\
& 994. Glycerol-3-phosphate dehydrogenase \\
& 1000. Glycerol-3-phosphate dehydrogenase \\
& 1017. IP10437p \\
1029. Probable transaldolase & 112. Drosocrystallin \\
679. Gene P1 protein & 711. Vitellogenin II precursor \\
716. Vitellogenin I precursor & 1502. Proteasome endopeptidase complex \\
Others & 324. Heat shock 70-kDa proten cognate
\end{tabular}

Protein folding, sorting, and degradation

Transport protein

324. Heat shock 70-kDa protein cognate 4

285. Transferrin precursor

1234. Ferritin 2 light chain homolog

Cell structure and mobility protein

297. Tropomyosin-1

300. Tropomyosin-2

513. Actin

562. Actin

571. Actin

750. Actin

1380. Cofilin/actin-depolymerizing factor homolog

Neuron development

1139. 14-3-3 protein

Function unknown

675. CG2233-PA

interaction map in Figure 3 shows at the 'medium' confidence level that more than $1 / 2(17 / 30 ; 57 \%)$ of the entered proteins could interact with one or more of the others. Succinate dehydrogenase B (SdhB) interacted with the highest number of input proteins (eight interactions) followed by cofilin/actin-depolymerizing factor (tsr), the vitellogenin I precursor (Yp1), heat shock $70-\mathrm{kDa}$ protein cognate 4 (HSc70-4), heat shock 60-kDa (Hsp60), and isocitrate dehydrogenase D (CG5028) with seven interactions. These interactions imply that many of the identified proteins occur within closely related signaling networks or biological pathways and are involved in regulating the 


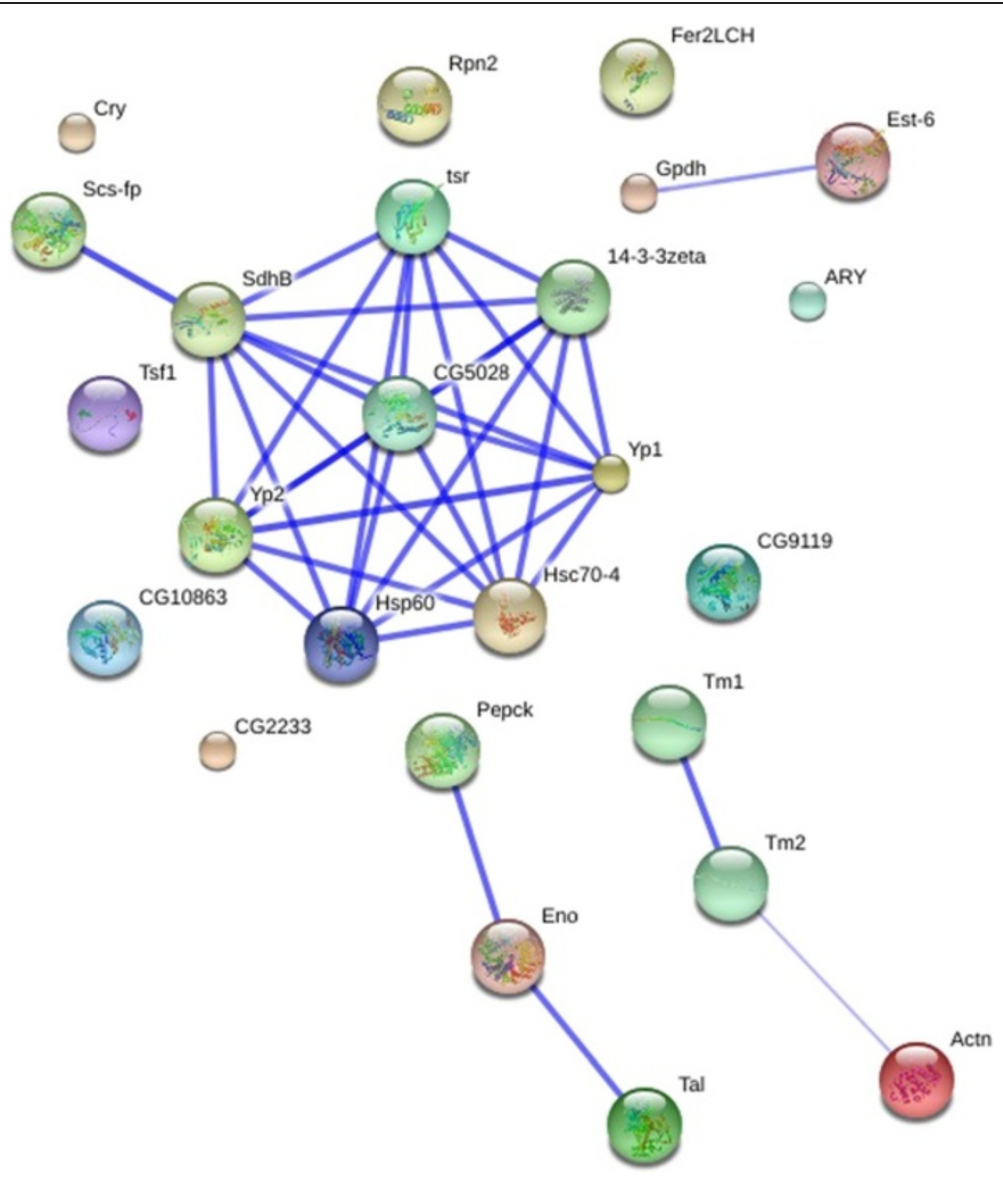

Figure 3 Interaction networks of identified proteins. Proteins identified in Table 1 were imported into the EMBL Search Tool for the Retrieval of Interacting Proteins (STRING) database (http://string.embl.de/), and an interaction map was generated. Each node represents a protein entry. Interactions or edges were generated from the experimental results, text mining, and database evidence using a medium confidence level. Thicker lines represent higher-confidence interactions.

trichloroacetic acid (TCA) cycle, protein folding, and cytoskeleton regulation. This further suggests that mitochondrial metabolic controls and protein conformational maintenance contribute to memory formation in Drosophila.

\section{Discussion}

Proteomic tools offer potential opportunities to investigate global cellular processes by directly visualizing a comprehensive set of gene products. In the current study, 2-DE was used to separate thousands of proteins by $2 \mathrm{D}-\mathrm{PAGE}$ according to their relative $\mathrm{p} I \mathrm{~s}$ and molecular weights (Gorg et al. 2004).

Fly brains are difficult to obtain; therefore, the reason we performed a differential proteome analysis was to show that there was high overlap of proteins found in both the head and brain, and we could simply substitute the head for the brain in further studies. We analyzed the proteomes of heads, brains, and cuticles, and compared differences in proteome expression patterns using the 2D-DIGE technique. Heads of fruit flies were carefully dissected and separated into two parts, brains and cuticles. Proteins from the heads, brains, and cuticles were extracted and consequently labeled with fluorescence dyes $(\mathrm{Cy} 2, \mathrm{Cy} 3$, and Cy5). After separation by 2D-PAGE, CyDye ${ }^{\mathrm{ru}}$-labeled protein spots could be visualized using a fluorescence scanner. Proteins found in the heads and brains were approximately $90 \%$ similar (Figure 4 ). In contrast, there was $<30 \%$ overlap of proteins found in the brain and cuticle (Figure 5). Theoretically, the sum of proteins found in both the brain and cuticle should equal total proteins found in the head. In summary, these results showed that there was about a $10 \%$ protein difference between the head and brain proteomes. In order to facilitate analysis of differential protein expressions involved in memory formation by proteomics research, the brain proteomic analysis was replaced with a head proteomic analysis in this study to perform experiments comparing brain function-related proteomes.

In the current study, flies with mutated $A m n^{X 8}$ possessed normal learning and memory behaviors during 


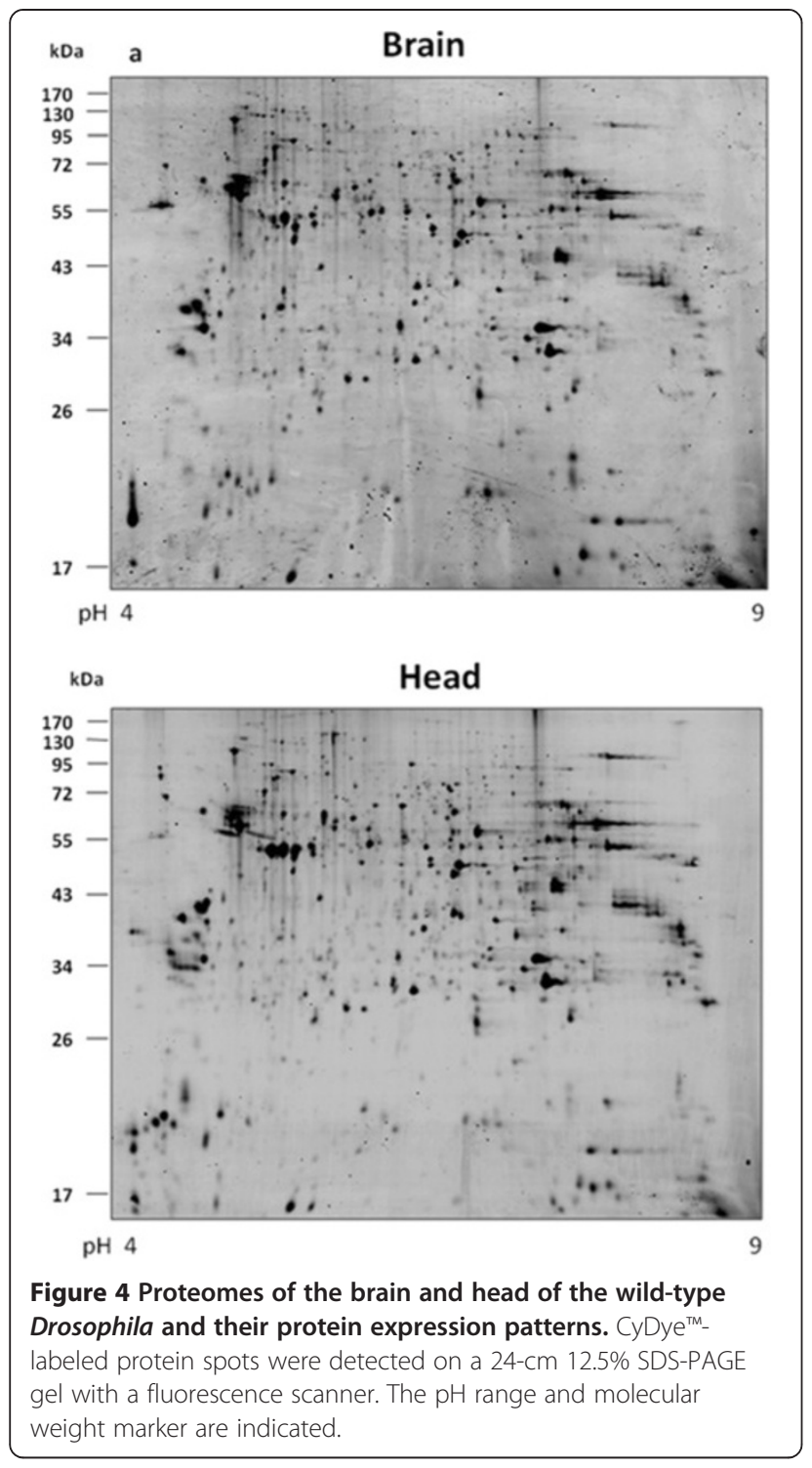

the first $30 \mathrm{~min}$ of training compared to their normal controls $(2 u)$ as examined by a proteomics analysis where a total of 30 proteins that differed in protein expression levels between the $2 u$ and $A m n^{X 8}$ strains were identified. The 14-3-3 protein (spot no. 1139) was shown to be more abundant (by 9.26-fold) in the WT $2 u$ strain. Research on Drosophila melanogaster and other insects indicated that the 14-3-3 protein is encoded by the leonardo gene ( $88 \%$ amino acid identity to the mammalian 14-3-3 $\zeta$ isoform), is dominantly distributed in the central nervous system preferentially in the $\mathrm{MB}$, and plays essential roles in learning and memory (Watanabe et al. 1993). The leonardo gene product was found to modulate pre-synaptic function (Skoulakis and Davis 1996; Broadie et al. 1997). If the alleles were mutated, leonardo protein expression was downregulated in MBs which significantly affected olfactory learning, but the mutation did not affect sensory modalities. Thus, results from previous reports and our experiments indicated that the 14-3-3 protein plays an important role in memory formation.

Numerous identified proteins were involved in energy metabolic pathways. Phosphoenolpyruvate carboxykinase (spot no. 351) is involved in glycolysis/gluconeogenesis and the citric acid cycle pathway. The succinate dehydrogenase ubiquinone subunit (spot no. 408) participates in the citric acid cycle and oxidative phosphorylation. Isocitrate dehydrogenase isoform D (spot no. 740) is also involved in the TCA cycle. All of these proteins were found to be upregulated in the $2 u$ fly brain compared to $A m n^{X 8}$, which implies that sufficient energy is essential for maintaining cell survival. Notably, glucose is a major fuel source for the brain due to its ability to cross the bloodbrain barrier. Energy metabolism in animal brains relies on glycolysis and glycogenolysis to modulate neuron transmissions (Hertz et al. 2007). Additionally, astrocytes are responsible for $20 \%$ of glucose consumption in the brain and generate glutamate and glutamine which play important roles as neurotransmitters and are associated with learning, memory, and other neuronal functions (Hertz and Kala 2007; McGahan et al. 2005; Montana et al. 2004). Accordingly, from our proteomics results and those of previous reports, the energetic production rate of WT flies is probably higher than that of memory-deficient mutant flies.

Interestingly, glycerol-3-phosphate dehydrogenase, a glycolytic protein, was identified as two doublet spots with similar molecular weights but different $\mathrm{p} I \mathrm{~s}$ in the 2D-DIGE analysis (Figure 1). The pink spots (spot nos.

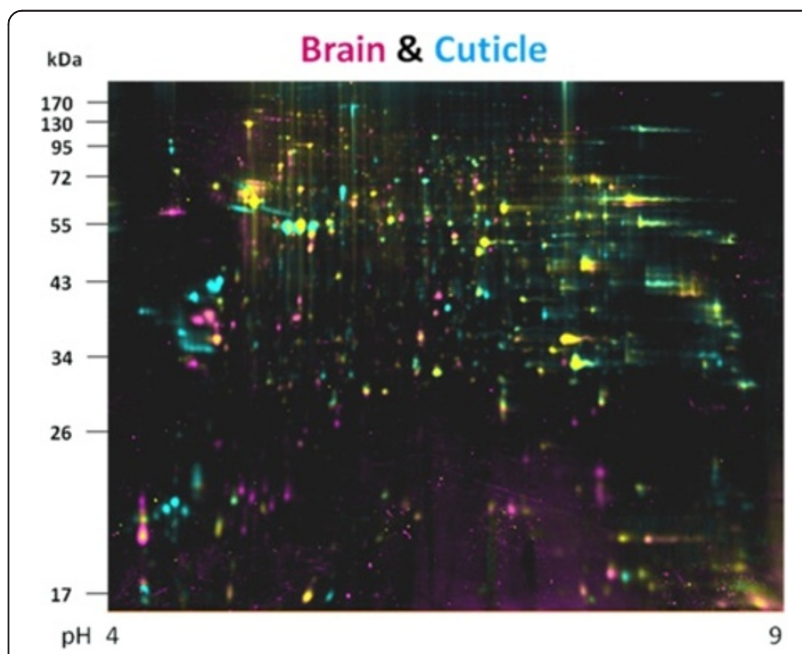

Figure 5 Image superimposition of the Drosophila brain and cuticle. 2D-DIGE images of the brain and cuticle are superimposed. Brain proteins are labeled in red, and cuticle proteins are labeled in blue. Yellow-colored spots represent proteins expressed in both the brain and cuticle. 
982 and 994) were upregulated in WT $2 u$ flies; in contrast, the green spots (spot nos. 989 and 1000) were upregulated in memory-deficient mutant $A m n^{X 8}$ flies. We propose that the $\mathrm{p} I$ shift in 2D-DIGE was caused by post-translational modification, such as by phosphorylation. Additionally, intracellular glycerol may have two roles in energy production. First, it may take part in ATP formation by [entering] glycolysis and oxidative metabolism. Second, glycerol-3-phosphate may serve as a glycerol-3-phosphate shuttle, which translocates reducing equivalents into mitochondria (Nguyen et al. 2003). Hence, glycerol-3-phosphate dehydrogenase in the brain was assumed to play a critical function in energy metabolism (Kageoka et al. 1985; Wells et al. 2001).

Iron homeostasis is essential for normal cognitive development and functioning of the brain. In a recent study, a proper iron balance was reported to facilitate learning and neuron plasticity (Carlson et al. 2009) by regulating downstream glutamate production and glutamate secretion (McGahan et al. 2005). Among the proteins we identified, there were two iron-related proteins which were upregulated in $A m n^{X 8}$ flies. One was the transferrin precursor (spot no. 285). Transferrin, an iron ion transport protein, can help maintain iron concentrations in cells. The other was ferritin 2 light chain homo$\log$ (spot no. 1234). Ferritin, an iron storage protein, is composed of 24 subunits including ferritin heavy and light polypeptides. These iron-related proteins were upregulated in $A m n^{X 8}$ flies compared to $2 u$ flies, suggesting a compensatory effect of the transferrin precursor (spot no. 285) and ferritin 2 light chain homolog (spot no. 1234).

Signal transmission is very complicated and rapid among neurons in order to regulate organism coordination. Accordingly, good efficacy of synaptic transmission can facilitate the trafficking of the synaptic machinery. Previous studies revealed that excitatory synapses play a critical role during learning and memory in the brain. Thus, the actin cytoskeleton is involved in the formation and function of the post-synaptic mushroom-shaped structure, dendritic spines, and possibly pre-synaptic terminals (Korobova and Svitkina 2010; Matus 2005; Cingolani and Goda 2008). Actin isoforms are major components of cellular scaffolding of cytoskeleton proteins. During neurogenesis, actin plays an important role in neurite formation, branching, and extension, and synaptogenesis (Cingolani and Goda 2008). Hence, it is a major cytoskeletal protein located at synapses including both pre- and post-synaptic terminals (Fifkova and Delay 1982). Comparing head protein profiles of $2 u$ and $A m n^{X 8}$ flies showed that four actins (spot nos. 513, 562, 571, and 750) were all upregulated in $2 u$ flies. In addition, short actin filaments at excitatory synapses interlink synaptic vesicles with each other in pre-synaptic terminals. Thus, they can facilitate synaptic vesicles, which carry neurotransmitters, moving to active zones (Cingolani and Goda 2008).

\section{Conclusions}

In this study, we successfully used proteomics to study learning- and memory-related proteins in the brain of the fruit fly. We employed 2D-DIGE and MALDI-TOF MS to compare brain proteomes between normal and memory-deficient mutant fruit flies. To our knowledge, this is the first publication with a comparative head proteomics memory-related analysis of fruit fly strains. The fundamental proteomics analysis offers potential candidates for further elucidation of the biological mechanisms of memory formation.

\section{Abbreviations}

2-DE: Two-dimensional gel electrophoresis; $\mathrm{ddH}_{2} \mathrm{O}$ : Double-deionized water; DIGE: Differential gel electrophoresis; MALDI-TOF MS: Matrix-assisted laser desorption ionization time of flight mass spectrometry; SDS: Sodium dodecyl sulfate.

\section{Competing interests}

The authors declare that they have no competing interests.

\section{Authors' contributions}

TRL, HYL, SHH, and HTC carried out the 2D-DIGE and proteomic experiments and conducted the statistical analysis. HLC and PCL conceived of the study, participated in its design and coordination, and drafted the manuscript. All authors read and approved the final manuscript.

\section{Acknowledgements}

This work was supported by a National Tsing Hua Univ. (NTHU, Hsinchu, Taiwan) Booster grant and a Nano- and Micro-ElectroMechanical Systemsbased Frontier Research on Cancer Mechanism, Diagnosis, and Treatment grant from NTHU. The authors also appreciate the kind provision of different fly strains by the Brain Research Center and Prof. Ann-Shyn Chiang's laboratory of NTHU. We also thank Prof. Ann-Shyn Chiang for the discussion and comments on the manuscript.

Received: 9 August 2012 Accepted: 31 January 2013

Published: 10 September 2013

\section{References}

Adams MD, Celniker SE, Holt RA, Evans CA, Gocayne JD, Amanatides PG, Scherer SE, Li PW, Hoskins RA, Galle RF, George RA, Lewis SE, Richards S, Ashburner M, Henderson SN, Sutton GG, Wortman JR, Yandell MD, Zhang Q, Chen LX, Brandon RC, Rogers YH, Blazej RG, Champe M, Pfeiffer BD, Wan KH, Doyle C, Baxter EG, Helt G, Nelson CR et al (2000) The genome sequence of Drosophila melanogaster. Science 287:2185-2195

Barco A, Alarcon JM, Kandel ER (2002) Expression of constitutively active CREB protein facilitates the late phase of long-term potentiation by enhancing synaptic capture. Cell 108:689-703

Broadie K, Rushton E, Skoulakis EM, Davis RL (1997) Leonardo, a Drosophila 14-3-3 protein involved in learning, regulates presynaptic function. Neuron 19:391-402

Carlson ES, Tkac I, Magid R, O'Connor MB, Andrews NC, Schallert T, Gunshin H, Georgieff MK, Petryk A (2009) Iron is essential for neuron development and memory function in mouse hippocampus. J Nutr 139:672-679

Celotto AM, Palladino MJ (2005) Drosophila: a "model" model system to study neurodegeneration. Mol Interv 5:292-303

Chan HL, Gharbi S, Gaffney PR, Cramer R, Waterfield MD, Timms JF (2005) Proteomic analysis of redox- and ErbB2-dependent changes in mammary luminal epithelial cells using cysteine- and lysine-labelling two-dimensional difference gel electrophoresis. Proteomics 5:2908-2926

Chen YW, Chou HC, Lyu PC, Yin HS, Huang FL, Chang WS, Fan CY, Tu IF, Lai TC, Lin ST, Lu YC, Wu CL, Huang SH, Chan HL (2011) Mitochondrial proteomics 
analysis of tumorigenic and metastatic breast cancer markers. Funct Integr Genomics 11:225-239

Chou HC, Chen YW, Lee TR, Wu FS, Chan HT, Lyu PC, Timms JF, Chan HL (2010) Proteomics study of oxidative stress and Src kinase inhibition in $\mathrm{H} 9 \mathrm{C2}$ cardiomyocytes: a cell model of heart ischemia reperfusion injury and treatment. Free Radic Biol Med 49:96-108

Cingolani LA, Goda Y (2008) Actin in action: the interplay between the actin cytoskeleton and synaptic efficacy. Nat Rev Neurosci 9:344-356

DeZazzo J, Tully T (1995) Dissection of memory formation: from behavioral pharmacology to molecular genetics. Trends Neurosci 18:212-218

Dubnau J, Chiang AS, Grady L, Barditch J, Gossweiler S, McNeil J, Smith P, Buldoc F, Scott R, Certa U, Broger C, Tully T (2003) The staufen/pumilio pathway is involved in Drosophila long-term memory. Curr Biol 13:286-296

Ericsson C (1999) 2-D protein extracts from Drosophila melanogaster. Methods Mol Biol 112:35-41

Fifkova E, Delay RJ (1982) Cytoplasmic actin in neuronal processes as a possible mediator of synaptic plasticity. J Cell Biol 95:345-350

Gharbi S, Gaffney P, Yang A, Zvelebil MJ, Cramer R, Waterfield MD, Timms Jf (2002) Evaluation of two-dimensional differential gel electrophoresis for proteomic expression analysis of a model breast cancer cell system. Mol Cell Proteomics 1:91-98

Gorg A, Weiss W, Dunn MJ (2004) Current two-dimensional electrophoresis technology for proteomics. Proteomics 4:3665-3685

Hertz L, Kala G (2007) Energy metabolism in brain cells: effects of elevated ammonia concentrations. Metab Brain Dis 22:199-218

Hertz L, Peng L, Dienel GA (2007) Energy metabolism in astrocytes: high rate of oxidative metabolism and spatiotemporal dependence on glycolysis/ glycogenolysis. J Cereb Blood Flow Metab 27:219-249

Huang HL, Hsing HW, Lai TC, Chen YW, Lee TR, Chan HT, Lyu PC, Wu CL, Lu YC, Lin ST, Lin CW, Lai CH, Chang HT, Chou HC, Chan HL (2010) Trypsin-induced proteome alteration during cell subculture in mammalian cells. J Biomed Sci 17:36

Hung PH, Lu YC, Chen YW, Chou HC, Lyu PC, Lee YR, Chan HL (2010) Proteomic identification of plasma biomarkers in type 2 diabetic nephropathy. J Integrated OMICS 1:151-154

Hung PH, Chen YW, Cheng KC, Chou HC, Lyu PC, Lu YC, Lee YR, Wu CT, Chan HL (2011) Plasma proteomic analysis of the critical limb ischemia markers in diabetic patients with hemodialysis. Mol Biosyst 7:1990-1998

Kageoka T, Satoh C, Goriki K, Fujita M, Neriishi S, Yamamura K, Kaneko J, Masunari N (1985) Electrophoretic variants of blood proteins in Japanese. IV. Prevalence and enzymologic characteristics of glucose-6-phosphate dehydrogenase variants in Hiroshima and Nagasaki. Hum Genet 70:101-108

Korobova F, Svitkina T (2010) Molecular architecture of synaptic actin cytoskeleton in hippocampal neurons reveals a mechanism of dendritic spine morphogenesis. Mol Biol Cell 21:165-176

Lai TC, Chou HC, Chen YW, Lee TR, Chan HT, Shen HH, Lee WT, Lin ST, Lu YC, Wu $\mathrm{CL}$, Chan HL (2010) Secretomic and proteomic analysis of potential breast cancer markers by two-dimensional differential gel electrophoresis. J Proteome Res 9:1302-1322

Matus A (2005) Growth of dendritic spines: a continuing story. Curr Opin Neurobiol 15:67-72

McGahan MC, Harned J, Mukunnemkeril M, Goralska M, Fleisher L, Ferrell JB (2005) Iron alters glutamate secretion by regulating cytosolic aconitase activity. Am J Physiol Cell Physiol 288:C1117-C1124

Montana V, Ni Y, Sunjara V, Hua X, Parpura V (2004) Vesicular glutamate transporter-dependent glutamate release from astrocytes. I Neurosci 24:2633-2642

Mutsuddi M, Nambu JR (1998) Neural disease: Drosophila degenerates for a good cause. Curr Biol 8:R809-R811

Nguyen NH, Brathe A, Hassel B (2003) Neuronal uptake and metabolism of glycerol and the neuronal expression of mitochondrial glycerol-3-phosphate dehydrogenase. J Neurochem 85:831-842

Quinn WG, Sziber PP, Booker R (1979) The Drosophila memory mutant amnesiac. Nature 277:212-214

Skoulakis EM, Davis RL (1996) Olfactory learning deficits in mutants for Leonardo, a Drosophila gene encoding a 14-3-3 protein. Neuron 17:931-944

Timms JF (2008) Protein technologies. Curr Opin Biotechnol 19:313-315

Timms JF, Cramer R (2008) Difference gel electrophoresis. Proteomics 8:4886-4897

Tully T, Quinn WG (1985) Classical conditioning and retention in normal and mutant Drosophila melanogaster. J Comp Physiol A 157:263-277

Venken KJ, Bellen HJ (2005) Emerging technologies for gene manipulation in Drosophila melanogaster. Nat Rev Genet 6:167-178
Venken KJ, Bellen HJ (2007) Transgenesis upgrades for Drosophila melanogaster. Development 134:3571-3584

Waddell S, Quinn WG (2001) Neurobiology. Learning how a fruit fly forgets. Science 293:1271-1272

Waddell S, Armstrong JD, Kitamoto T, Kaiser K, Quinn WG (2000) The amnesiac gene product is expressed in two neurons in the Drosophila brain that are critical for memory. Cell 103:805-813

Watanabe M, Isobe T, Ichimura T, Kuwano R, Takahashi Y, Kondo H (1993) Molecular cloning of rat cDNAs for beta and gamma subtypes of 14-3-3 protein and developmental changes in expression of their mRNAs in the nervous system. Brain Res Mol Brain Res 17:135-146

Wells WW, Xu DP, Washburn MP, Cirrito HK, Olson LK (2001)

Polyhydroxybenzoates inhibit ascorbic acid activation of mitochondrial glycerol-3-phosphate dehydrogenase: implications for glucose metabolism and insulin secretion. J Biol Chem 276:2404-2410

doi:10.1186/1810-522X-52-10

Cite this article as: Lee et al:: Comparative proteomics analysis of normal and memory-deficient Drosophila melanogaster heads. Zoological Studies 2013 52:10.

\section{Submit your manuscript to a SpringerOpen ${ }^{\odot}$ journal and benefit from:}

- Convenient online submission

- Rigorous peer review

- Immediate publication on acceptance

- Open access: articles freely available online

High visibility within the field

- Retaining the copyright to your article

Submit your next manuscript at $\gg$ springeropen.com 